\title{
Pendapatan dan Produksi Potensial Usahatani Konservasi Lahan Pantai Di Kabupaten Bantul
}

\author{
Income and Production Potential of \\ Conservation Farming at Coastal Land in \\ Bantul
}

D 0 : 10.18196/ agr.111

\begin{abstract}
Coastal land management are expected not only serves as an erosion control (wind), but also serves to increase farmer's incomes. This study aims to analyze the income and the potential production of conservation farming system on coastal land in Bantul. The survey was conducted in the village of Srigading and Gadingsari Bantul. Income and potential production of four main commodities, namely red onions, red peppers, eggplant, and sweet potatoes were analyzed using Technical Efficiency Effect Model. Results of the study showed that from 0.1 hectares of coastal land, the farmers obtain the highest revenue of red pepper, which amounted to Rp 3.9 million in the dry season 1 and Rp 2.5 in the dry season 2; followed by
\end{abstract}

red onions income, amounted to Rp 2.1 million in the rainy season and Rp1.6 in the dry season; while eggplant provide the lowest income, which amounted to Rp 98 thousand in the rainy season. The estimation results of Cobb-Douglas Stochastic Frontier Model with MLE method showed an increase in the potential of onion in the rainy season by $7.4 \%$; eggplant $11.4 \%$ and $10.2 \%$ sweet potato. In the dry season 1 , there is an increase in onion production by $10.6 \%$; red chili $4 \%$ and $5.6 \%$ sweet potato. While in the dry season 2 , there is an increased production of red onion and eggplant by $4.1 \%$ at $6.1 \%$.

Keywords: Conservation Farming, Coastal Land, Technical Efficiency

\section{PENDAHULUAN}

Berdasarkan keputusan Menteri Kelautan dan Perikanan Nomor 10/ Men/2002 tentang pedoman umum perencanaan pengelolaan pesisir terpadu dan UU No. 5 Tahun 1990 tentang konservasi sumber daya alam hayati dan ekosistemnya; dan pentingnya pesisir pantai yang kaya akan sumber daya alam dan jasa lingkungan, hendaknya pemanfaatan pesisir pantai dilakukan dengan baik dan benar serta mampu berfungsi ganda. Berfungsi ganda artinya pengelolaan lahan pantai selain berfungsi sebagai pengendali erosi (angin) juga berfungsi meningkatkan pendapatan masyarakat melalui usaha budidaya tanaman yang sesuai dan bernilai ekonomis.

Salah satu permasalahan wilayah pantai dari segi iklim adalah kenaikan air laut yang dapat menyebabkan abrasi pantai, sedimentasi dan erosi berlebihan. Dampak peristiwa erosi pasir antara lain: 1) tanah pada lahan pantai bertekstur kasar dan bersifat lepas sehingga sangat peka terhadap erosi angin, 2) hasil erosi yang berupa endapan pasir (sand dune) mampu menutup wilayah budidaya pertanian dan pemukiman didaerah dibelakangnya, 3) butiran pasir bergaram yang dibawa dari proses erosi angin dapat merusak dan menurunkan produktivitas tanaman budidaya. Peristiwa tersebut menyebabkan lahan pantai berpasir menjadi kritis dan 
harus segera mendapatkan penanganan (Triatmodjo, 1999; Tim UGM, 1992, Haryadi B., 2009; Suryanto, 1996 dalam Budiyanto, dkk., 2005).

Menurut Sukresno (Haryadi B., 2009), hal yang sangat penting dalam melakukan konservasi lahan pantai berpasir adalah dengan melakukan penanaman tanaman tanggul angin/ pemecah angin (cemara laut, Glirisidae, pandan dan mete) dan pengusahaan tanaman budidaya hortikultura yang ditanam diantara tanaman tanggul angin. Usaha budidaya hortikultura, lahan pantai memerlukan dua syarat pokok yaitu ketersediaan air dan bahan organic. Teknologi yang digunakan adalah dengan pengadaan sumur renteng dan pemberian pupuk kandang.

Weersink, dkk., (Adiyoga W., 1999) menjelaskan bahwa tingkat pendapatan usahatani sangat ditentukan oleh efisiensi petani untuk mengalokasikan sumberdaya yang dimilikinya kedalam berbagai alternative aktivitas produksi. Apabila petani tidak menggunakan sumberdaya secara efisien, maka akan terdapat potensi yang tidak/ belum tereksploitasi untuk meningkatkan pendapatan.

\section{METODE PENELITIAN}

Penelitian ini menggunakan metode survey dengan lokasi penelitian di Kabupaten Bantul, Daerah Istimewa Yogyakarta. Sampel kecamatan dan desa ditetapkan secara purposif, yaitu sepanjang pantai Samas di Kecamatan Sanden, dengan sampel desa di Desa Srigading dan Gadingsari. Daerah tersebut merupakan daerah konservasi dan kegiatan usahatani lahan pantai yang telah berlangsung lama yaitu sejak tahun 1996 dan merupakan daerah pantauan konservasi dari Dinas Kehutanan, Pertanian, Peternakan dan Pesisir, Kelautan dan Perikanan Kab. Bantul.

Metode penarikan sampel petani yang digunakan dalam penelitian ini adalah dengan proporsional random sampling yaitu suatu teknik pengambilan sampel secara acak dengan jumlah yang proporsional untuk setiap sub populasi (kelompok tani) sesuai dengan ukuran populasinya (Sekaran, 2003). Teknik pengumpulan data menggunakan tiga macam cara, yakni teknik wawancara, observasi dan pencatatan.

Besarnya pendapatan yang diterima petani dihitung menggunakan rumussebagai berikut:

$\mathrm{NR}=\mathrm{TR}-\mathrm{TC}_{\text {eksplisit }}$

Keterangan :

$\mathrm{NR}=$ Net Revenue (pendapatan)
$\mathrm{TR}=$ Total Revenue (total penerimaan)
$\mathrm{TC}_{\text {eks }}=$ Total Cost eksplisit (total biaya)

Teknik analisis untuk efisiensi teknis diawali dengan persamaan untuk fungsi produksi usahatani (bawang merah, cabai merah, terong dan ubi jalar) lahan pantai yaitu:

$\operatorname{Ln} Y=a ́+\hat{a}_{1} \ln X_{1}+\hat{a}_{2} \ln X_{2}+\hat{a}_{3} \ln X_{3}+\hat{a}_{4} \ln X_{4}+\hat{a}_{5}$ $\ln \mathrm{X}_{5}+\hat{a}_{6} \ln \mathrm{X}_{6}+\hat{a}_{7} \ln \mathrm{X}_{7}+\left(\mathrm{v}_{\mathrm{i}}-\mathrm{u}_{\mathrm{i}}\right)$

Keterangan :

$\mathrm{Y}=\operatorname{produksi}(\mathrm{kg})$

á $=$ intersep

$\hat{\mathrm{a}}_{\mathrm{i}}=$ koefisien regresi (parameter yang ditaksir) $(\mathrm{i}=1 \mathrm{~s} / \mathrm{d}$ 7)

$\mathrm{X}_{1}=$ luas lahan (ha)

$\mathrm{X}_{2}=$ tenaga kerja $(\mathrm{HOK})$

$\mathrm{X}_{3}=$ pupuk an-organik $(\mathrm{kg})$

$\mathrm{X}_{4}=$ pupuk organik $(\mathrm{kg})$

$\mathrm{X}_{5}=$ Sumur renteng (unit)

$\mathrm{X}_{6}=$ Windbarier (unit)

$\mathrm{X}_{7}=$ pestisida (liter)

$\mathrm{v}_{\mathrm{i}}-\mathrm{u}_{\mathrm{i}}=$ error term, $\left(\mathrm{u}_{\mathrm{i}}\right)$ efek inefisiensi teknis dalam model

Tanda parameter yang diharapkan : $\hat{a}_{1,} \hat{a}_{2,} \hat{a}_{3,} \hat{a}_{4,} \hat{a}_{5,} \hat{a}_{6,} \hat{a}_{7}>0$

Tahapan analisis selanjutnya adalah pendugaan parameter fungsi produksi stochastic frontier dan inefficiency function dilakukan secara simultan dengan program Frontier 4.1 (Coelli, 1996). Pendugaan seluruh parameter $\hat{a}_{0}$, âi, varians $u_{i}$ dan $v_{i}$ dengan menggunakan metode Maximum Likelihood Estimation (MLE) dengan pilihan Technical Efficiency Effect Model.

Model inefisiensi teknis :

$\mathrm{u}_{\mathrm{i}}=\tilde{\mathrm{N}}_{0}+\tilde{\mathrm{N}}_{1} \mathrm{Z}_{1}+\tilde{\mathrm{N}}_{2} \mathrm{Z}_{2}+\tilde{\mathrm{N}}_{3} \mathrm{Z}_{3}+\tilde{\mathrm{N}}_{4} \mathrm{Z}_{4}+\tilde{\mathrm{N}}_{5} \mathrm{Z}_{5}+\tilde{\mathrm{N}}_{\mathrm{sl}} \mathrm{Z}_{\mathrm{sl}}$ dimana :

$\mathrm{u}_{\mathrm{i}} \quad=$ efek inefisiensi teknis

$\tilde{\mathrm{N}}=$ koefisien inefisiensi teknis

$Z_{1} \quad=$ umur petani (tahun)

$\mathrm{Z}_{2} \quad$ = tingkat pendidikan formal petani (tahun)

$\mathrm{Z}_{3} \quad$ = pengalaman usahatani padi sawah (tahun)

$\mathrm{Z}_{4} \quad$ = jumlah anggota rumah tangga (jiwa)

$Z_{5} \quad=$ frekuensi mengikuti penyuluhan (pertemuan)

Tahapan analisis berikutnya adalah analisis efisiensi teknis yang dapat diukur dengan menggunakan rumus berikut: 
TABEL I. ANALISIS PENDAPATAN USAHATANI KONSERVASI TANAMAN HORTIKULtURA DAN TANAMAN PANGAN DI LAHAN PANTAI, KABUPATEN baNTUL (0.I HA).

\begin{tabular}{|c|c|c|c|c|c|c|c|c|}
\hline Musim & \multicolumn{3}{|c|}{ Musim Hujan } & \multicolumn{3}{|c|}{ Musim Kemarau 1} & \multicolumn{2}{|c|}{ Musim Kemarau 2} \\
\hline Jenis Tanaman & $\begin{array}{l}\text { Bawang } \\
\text { Merah (Rp) }\end{array}$ & $\begin{array}{l}\text { Terong } \\
\text { (Rp) }\end{array}$ & $\begin{array}{l}\text { Ubi Jalar } \\
\text { (Rp) }\end{array}$ & $\begin{array}{l}\text { Bawang } \\
\text { Merah (Rp) }\end{array}$ & $\begin{array}{l}\text { Cabai Merah } \\
\text { (Rp) }\end{array}$ & $\begin{array}{l}\text { Ubi Jalar } \\
\text { (Rp) }\end{array}$ & $\begin{array}{l}\text { Cabai Merah } \\
\text { (Rp) }\end{array}$ & $\begin{array}{l}\text { Ubi Jalar } \\
\text { (Rp) }\end{array}$ \\
\hline Penerimaan & $5,265,124$ & $1,846,117$ & $3,561,056$ & $5,189,622$ & $6,034,946$ & $2,755,995$ & $5,467,700$ & $4,409,377$ \\
\hline Total Biaya Eksplisit & $2,913,758$ & $1,692,719$ & $2,160,344$ & $3,326,128$ & $1,841,624$ & $1,924,365$ & $2,745,702$ & $1,871,166$ \\
\hline Pendapatan & $2,351,365$ & 153,397 & $1,400,712$ & $1,863,493$ & $4,193,321$ & 831,629 & $2,721,997$ & $2,538,211$ \\
\hline
\end{tabular}

Sumber: data primer diolah.

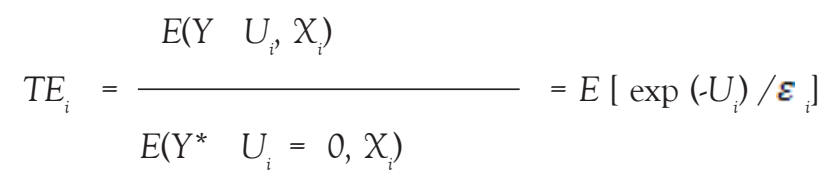

Dimana $T E_{i}$ adalah efisiensi teknis petani ke-i, exp( $\left.E\left[u_{i} \mid a_{i}\right]\right)$ adalah nilai harapan (mean) dari $u_{i}$ dengan syarat $\stackrel{a}{i}_{i}$, jadi $0 \leq T E_{i} \leq 1$. Metode efisiensi teknis yang digunakan dalam penelitian ini mengacu kepada model efek inefisiensi teknis yang dikembangkan Coelli et al., (1998). Tingkat efisiensi akan digunakan untuk mengetahui produksi potensial tiap komoditas.

\section{HASIL DAN PEMBAHASAN}

\section{PENDAPATAN USAHATANI KONSERVASI LAHAN PANTAI}

Pola usahatani yang dilakukan oleh petani lahan pantai adalah kombinasi antara usahatani tanaman hortikultura dan tanaman pangan (bawang merah, cabai merah, terong dan ubi jalar) dengan usaha ternak yaitu sapi, kambing dan unggas dan dengan melakukan penanaman tanaman konservasi terutama cemara udang dan pengadaan system irigasi sumur renteng. Penelitian ini memfokuskan pada analisis pendapatan usahatani tanaman hortikultura dan tanaman pangan yaitu bawang merah, cabai merah, terong dan ubi jalar selama tiga musim tanam.

Tabel 1 menjelaskan bahwa pada musim hujan tanaman bawang merah memiliki pendapatan tertinggi, namun demikian ubi jalar juga memiliki potensi untuk dikembangkan karena mampu memberikan pendapatan yang cukup tinggi juga. Pada musim kemarau 1, tanaman cabai merah memiliki pendapatan tertinggi dengan $\mathrm{Rp}$ 4,193,321.- dan menjadi pendapatan tertinggi juga pada setiap musim. Musim kemarau 1 dianggap musim terbaik bagi tanaman hortikultura di lahan pantai. Pada musim kemarau 2, cabai merah dan ubi jalar memiliki pendapatan yang hampir sama. Hal tersebut menunjukan bahwa keduanya berpeluang untuk diusahakan walaupun pendapatannya tidak setinggi musim kemarau 1.

Pada usahatani konservasi lahan pantai terdapat biaya pemeliharaan sumur renteng dan windbarier serta pupuk kandang. Luas lahan 0.1 ha rata-rata memerlukan sumur renteng sejumlah 9 (bis beton) dengan biaya pemeliharaan permusim sebesar $\mathrm{Rp}$ 18,333.- dan memerlukan tanaman windbarier sejumlah 8 tanaman dengan biaya pemeliharaan sebesar Rp 106,370.-.

\section{PRODUKSI POTENSIAL USAHATANI KONSERVASI LAHAN PANTAI}

Setiap produksi usahatani pasti memiliki sejumlah produksi potensial. Namun, dengan adanya keterbatasan usahatani maka petani kesulitan untuk mencapai produksi potensial. Salah satu keterbatasan yang juga sering menghambat adalah kemampuan manajemen petani itu sendiri.

Manajemen sebagai salah satu faktor produksi dan akan mempengaruhi kondisi usahatani. Kemampuan manajerial seorang petani sebagai pengelola dapat didekati dengan tingkat efisiensi teknis yang diperoleh dari estimasi fungsi produksi frontier. Untuk dapat menganalisis faktor-faktor yang mempengaruhi tingkat efisiensi teknik hal pertama yang harus dilakukan adalah mengukur tingkat efisiensi teknik masing-masing responden petani pada tiap komoditas.

Tabel 2. menjelaskan tingkat inefisiensi yang ditunjukan oleh hasil coefficient gamma. Coefficient gamma sebenarnya error term $(\mathrm{Vi}-\mathrm{Ui})$ yang dipengaruhi oleh delta (factor manajemen). Apabila nilai gamma kecil, 
TABEL 2. TINGKAT EFISIENSI DAN INEFISIENSI TIAP KOMODITAS PADA USAHATANI LAHAN PANTAI DI KAB. BANTUL.

\begin{tabular}{|c|c|c|c|c|c|c|c|}
\hline \multirow{2}{*}{ Musim } & \multirow{2}{*}{ Komoditas } & \multirow{2}{*}{$\begin{array}{l}\text { Coefficient } \\
\text { Gamma }\end{array}$} & \multirow{2}{*}{ t-ratio } & \multicolumn{2}{|c|}{ Mean Efficiency } & \multicolumn{2}{|c|}{ Potensi Peningkatan Produksi } \\
\hline & & & & Value & (\%) & Value & $(\%)$ \\
\hline \multirow{3}{*}{ Hujan } & Bawang Merah & 0,986 & 8,865 & 0,926 & 92,6 & 0,074 & 7,4 \\
\hline & Terong & 0,996 & 90,699 & 0,886 & 88,6 & 0,114 & 11,4 \\
\hline & Ubi Jalar & 0,981 & 6,212 & 0,898 & 89,8 & 0,102 & 10,2 \\
\hline \multirow{3}{*}{ Kemarau 1} & Bawang Merah & 0,932 & 30,571 & 0,894 & 89,4 & 0,106 & 10,6 \\
\hline & Cabai Merah & 0,549 & 1,439 & 0,960 & 96,0 & 0,040 & 4,0 \\
\hline & Ubi Jalar & 0,644 & 1,298 & 0,944 & 94,4 & 0,056 & 5,6 \\
\hline \multirow{2}{*}{ Kemarau 2} & Cabai Merah & 0,904 & 3,945 & 0,959 & 95,9 & 0,041 & 4,1 \\
\hline & Ubi Jalar & 0,999 & 22,214 & 0,939 & 93,9 & 0,061 & 6,1 \\
\hline
\end{tabular}

maka ada kemungkinan dipengaruhi oleh factor diluar inefisiensi atau delta tersebut. Mean efficiency menunjukan tingkat efisiensi sehingga selisih antara tingkat efisiensi dengan 1 (satu) merupakan besarnya potensi untuk memaksimalkan produksi.

Seluruh komoditas pada musim hujan dan musim kemarau 2 memiliki nilai gamma yang cukup tinggi yaitu diatas 0,9 dan memiliki t-ratio cukup tinggi sehingga sangat signifikan yang berarti bahwa variable manajemen yang meliputi umur, pengalaman, frekuensi mengikuti penyuluhan, pendidikan dan tenaga kerja dalam keluarga berpengaruh terhadap inefisiensi. Pada musim kemarau 1 hanya komoditas bawang merah yang sangat signifikan sedangkan komoditas cabai merah dan ubi jalar memiliki nilai gamma sebesar 0,55 dan 0,66 dengan t-ratio sebesar 1,44 dan 1,29. Nilai tersebut menjelaskan bahwa ada sebagian atau kemungkinan produksi dipengaruhi oleh factor diluar inefisiensi walaupun t-ratio menyimpulkan masuk dalam kategori signifikan.

Tabel 2 juga menjelaskan bahwa nilai mean efficiency yang bervariasi antar komoditas antara 0,89 (89 \%) sampai dengan 0,96 (96\%), sehingga potensi peningkatan efisiensi berkisar antara $4 \%$ sampai dengan $11 \%$. Berdasarkan nilai mean efficiency dapat diperoleh potensi peningkatan produksi ditiap komoditas dan potensi produksi maksimal. Secara rinci besarnya nilai potensi produksi maksimal di tiap musim tiap komoditas dapat dilihat pada Tabel 3.

\section{KESIMPULAN DAN IMPLIKASI KEBIJAKAN KESIMPULAN}

1. Tanaman bawang merah memiliki pendapatan tertinggi pada musim hujan, namun demikian ubi jalar juga memiliki potensi untuk dikembangkan karena mampu memberikan pendapatan yang cukup tinggi juga. Pada musim kemarau 1, tanaman cabai merah memiliki pendapatan tertinggi dengan $\mathrm{Rp}$ 4,193,321.- dan menjadi pendapatan tertinggi pada setiap musim. Pada musim kemarau 2, cabai merah dan ubi jalar memiliki pendapatan yang hampir sama.

2. Usahatani bawang merah, cabai merah, ubi jalar dan terong memiliki potensi peningkatan produksi berkisar antara 4\% - 11,4\% dengan melakukan peningkatan faktor manajemen.

\section{IMPLIKASI KEBIJAKAN}

1. Pengadaan dan pemeliharaan variabel konservasi yang terdiri dari tanaman windbarier, sumur renteng atau system irigasi dan pupuk organic diperlukan dalam usahatani lahan pantai.

2. Tanaman bawang merah, cabai merah dan ubi jalar tepat untuk diusahakan di lahan pantai, sedangkan terong agak rentan terhadap gagal panen karena faktor lingkungan.

3. Faktor manajemen (pendidikan petani, pengalaman, frekuensi penyuluhan, tenaga kerja dalam keluarga dan umur petani) berpengaruh pada peningkatan produksi potensial. Pelatihan teknis dan manajemen perlu dilakukan terutama kepada petani muda yang potensial. 
TABEL. 3. POTENSI KENAIKAN PRODUKSI TIAP KOMODITAS PADA USAHATANI LAHAN PANTAI DI KABUPATEN BANTUL, TAHUN 2012.

\begin{tabular}{llll}
\hline Musim & Komoditas & Produksi Aktual & Produksi Potensial \\
\hline Hujan & Bawang Merah $(\mathrm{kg})$ & $8.589,11$ & $9.224,70$ \\
& Terong $(\mathrm{kg})$ & $9.438,23$ & $10.514,19$ \\
& Ubi Jalar $(\mathrm{kg})$ & $12.855,80$ & $14.167,09$ \\
Kemarau 1 & Bawang Merah $(\mathrm{kg})$ & $9.104,60$ & $10.069,69$ \\
& Cabai Merah $(\mathrm{kg})$ & $10.972,63$ & $11.411,54$ \\
& Ubi Jalar $(\mathrm{kg})$ & $14.391,62$ & $15.197,55$ \\
Kemarau 2 & Cabai Merah $(\mathrm{kg})$ & $10.935,40$ & $11.383,75$ \\
& Ubi Jalar $(\mathrm{kg})$ & $15.204,75$ & $16.132,24$ \\
\hline
\end{tabular}

\section{DAFTAR PUSTAKA}

Adiyoga W., 1999. Beberapa Alternatif Pendekatan untuk mengukur Efisiensi atau Inefisiensi dalam Usahatani. Informatika Pertanian Aigner, C.D., K. Lovell and P. Schmidt., 1977. Formulation and Estimation of Stochastic Frontier Production Function Models. Journal of Econometrics, 6: pp. 21-37.

Asikin, C. 2006. Beragribisnis yang Lestari di Lahan Pasir Pantai. Kepala Badan Ketahanan Pangan dan Penyuluhan Provinsi DIY. Yogyakarta.

Bappeda Kabupaten Bantul, 2007. Buku Perencanaan Pembangunan Kabupaten Bantul. Bantul.

Balai Pengkajian Teknologi Pertanian Yogyakarta, 2006. Sistem Irigasi Sumur Renteng. Yogyakara.

Budiyanto G., 2005. Dampak Aplikasi Batuan Zeolit Alam dan Nitrogen Terhadap Keragaan Vegetatif Tanaman Jagung di Lahan Pasir Pantai. Jurnal: Agr-UMY, XIV, (1): $1-13$.

Coelli, T.,1998. A Guide to Frontier Version 4.1: A Computer Program for Stochastic Frontier Production and Cost Function Estimation. Centre for Efficiency and Productivity Analysis, University of New England Armidale, New South Wales.

Dahuri, R; Rais Y; Putra S.G; Sitepu M.J, 2001. Pengelolaan Sumber Daya Pesisir dan Lautan secara Terpadu. PT Pradnya Paramita. Jakarta.

Departemen Kelautan dan Perikanan. 2003. Pokok Pikiran RUU Pengelolaan Wilayah Pesisir dalam http://www.dkp.go.id. Diakses Juli 2012.
Dinas Kelautan, Perikanan dan Peternakan Kabupaten Bantul, 2007. Rencana Strategis Pengelolaan Pesisir dan Laut Terpadu (RSPPLT). Daerah Istimewa Yogyakarta.

G.E. Battese dan T.J. Coelli, 1992). Frontier Production, Technical Efficiency dan Panel Data. The Journal of Productivity Analysis, 3, 153-169. Netherlands.

Haryadi B., 2009. Model Rehabilitasi Lahan dan Konservasi Tanah Pantai Berpasir. Laporan Hasil Penelitian, Badan Penelitian dan Pengembangan Kehutanan. Surakarta.

Sekaran, U. 2003. Research Methods for Business : A Skill Building Approach $2^{\text {nd }}$ Edition, John Wiley and Son. New York.

Sukresno. 1998. Pemanfaatan Lahan Terlantar di Pantai Berpasir Samas-Bantul DIY dengan Budidaya Semangka. Prosiding. Seminar Nasional dan Pertemuan Tahunan Komisariat Daerah Himpunan Ilmu Tanah Indonesia, HITI Komda Jawa Timur, Malang.

Triatmodjo, B. 1999. Teknik Pantai. Beta Offset. Yogyakarta. Tim UGM. 1992. Rencana Pengembangan Wilayah Pantai Jawa Tengah. F. Geografi UGM YogyakartaBRLKT Wilayah V, Ditjen RRL, Dephut, Semarang. 